\title{
Amyloid-Like Fibrils from a Diphenylalanine Capped with an Aromatic Fluorenyl
}

Didac Martí, Enric Mayans, Ana M. Gil, Angelica Díaz, Ana I. Jimenez, Ibraheem Yousef, Ina Keridou, Carlos Cativiela, Jordi Puiggali, and Carlos Alemán

Langmuir, Just Accepted Manuscript • DOI: 10.1021/acs.langmuir.8b03378 • Publication Date (Web): 19 Nov 2018

Downloaded from http://pubs.acs.org on November 21, 2018

\section{Just Accepted}

"Just Accepted" manuscripts have been peer-reviewed and accepted for publication. They are posted online prior to technical editing, formatting for publication and author proofing. The American Chemical Society provides "Just Accepted" as a service to the research community to expedite the dissemination of scientific material as soon as possible after acceptance. "Just Accepted" manuscripts appear in full in PDF format accompanied by an HTML abstract. "Just Accepted" manuscripts have been fully peer reviewed, but should not be considered the official version of record. They are citable by the Digital Object Identifier (DOI®). "Just Accepted" is an optional service offered to authors. Therefore, the "Just Accepted" Web site may not include all articles that will be published in the journal. After a manuscript is technically edited and formatted, it will be removed from the "Just Accepted" Web site and published as an ASAP article. Note that technical editing may introduce minor changes to the manuscript text and/or graphics which could affect content, and all legal disclaimers and ethical guidelines that apply to the journal pertain. ACS cannot be held responsible for errors or consequences arising from the use of information contained in these "Just Accepted" manuscripts. 
${ }^{1}$ Departament d'Enginyeria Química, EEBE, Universitat Politècnica de Catalunya, C/ Eduard Maristany, 10-14, Ed. I2, 08019, Barcelona, Spain

${ }^{2}$ Barcelona Research Center for Multiscale Science and Engineering, Universitat Politècnica de Catalunya, Eduard Maristany, 10-14, 08019, Barcelona, Spain

${ }^{3}$ Departamento de Quimica Organica, Instituto de Sintesis Quimica y Catalisis Homogenea (ISQCH), CSIC-Universidad de Zaragoza, 50009 Zaragoza, Spain ${ }^{4}$ ALBA Synchrotron Light Facility, C/ de la Llum 2-26, Cerdanyola del Valles, 08290 Barcelona, Spain

$\diamond$ Both authors contributed equally to this study

*cativiela@unizar.es, jordi.puiggali@upc.edu,and carlos.aleman@upc.edu 


\begin{abstract}
The self-assembly behavior of a diphenylalanine amphiphile blocked at the Cterminus with a 9-fluorenylmethyl ester and stabilized at the $\mathrm{N}$-terminus with a trifluoroacetate (TFA) anion, TFA·FF-OFm, has been examined. At low peptide concentration $(0.5 \mathrm{mg} / \mathrm{mL})$, long amyloid-like fibrils, which come from the fusion of two or more helical ribbons and/or thinner fibrils, organized in bundles or as individual entities are detected. Microbeam synchrotron radiation infrared spectroscopy have shown that TFA $\cdot F F-O F m$ molecules in amyloid-like fibrils arrange forming antiparallel $\beta$-sheets. Alteration of the experimental conditions to prioritize the thermodynamic contribution with respect to the kinetic one in the self-assembly process inhibits the organization of amyloid-like structures in favor of the formation of conventional fibrous structures. On the basis of experimental observations, a structural model where the individual antiparallel $\beta$-sheets are oriented in parallel has been proposed for TFA $\cdot \mathrm{FF}$ OFm amyloid-like fibrils.
\end{abstract}




\section{INTRODUCTION}

Controlling the self-assembly of organic molecules into highly ordered nano- and microstructures is a very interesting topic in supramolecular chemistry and materials science. ${ }^{1}$ In particular, due to the unique properties, one-dimensional morphologies, such as tubes and fibers have attracted much attention. ${ }^{2,3}$ Within this issue, the diphenylalanine dipeptide, L-Phe-L-Phe (FF), which is the core recognition motif of Alzheimer's $A \beta$ peptides is a captivating building block that spontaneously selfassembles into nanotubes and nanofibers through well-ordered and consistent processes. ${ }^{4-7}$ The stability of these structures was attributed to the directionality offered by a combination of hydrogen bonding and repeated phenyl stacking interactions. Consequently, FF displays more well-defined structures than longer homo-oligomers, as for example $\mathrm{FFF}^{8}$ and FFFF. ${ }^{9}$ In addition, FF has attracted increasing interest as building block due to its biocompatibility, functional molecular recognition, and unique biological and electronic properties. ${ }^{10-13}$

Due to its inherent self-assembly capacity, the FF has given place to the development of a new class of biomaterials that is based on the addition of $\mathrm{N}$ - and/or C-terminal capping groups to the aromatic FF or, even, on chemical modification of the own $\mathrm{F}$ residues. $^{8-17}$ The amphiphile Fmoc-FF, where Fmoc refers to fluorenylmethoxycarbonyl, is among the most studied capped FF-based biomaterials. This short peptide forms gels under very different experimental conditions, neighboring molecules interacting through hydrogen bonds and weak offset $\pi-\pi$ interactions. ${ }^{18-27}$ Similarly, Nap-FF (Nap= naphthalene) and $\mathrm{Cbz}-\mathrm{FF}$ ( $\mathrm{Cbz}=$ benzyloxycarbonyl) hydrogels showed fibrous structures made of $\beta$-sheet arrangements. ${ }^{28}$ On the other hand, the Fmoc-FF-OFm peptide, capped with Fmoc and 9-fluorenylmethyl ester (OFm) at the N- and C-terminus, respectively, exhibited a great variety of polymorphic self- 
assembled microstructures (e.g. doughnut, stacked-braids, dendritic and microtubes) depending on the solvents used to promote self-assembly processes. ${ }^{29}$ Advances on structural trends of assembled FF-based amphiphiles have been periodically reviewed along the last decade. ${ }^{30-33}$

In a recent study, we examined the self-assembly of a FF-based amphiphile that exhibited three main differences with respect to Fmoc-FF: ${ }^{34}(1)$ the size and (2) the position of the aromatic capping group, and (3) the stability of the free (charged) terminus. In this new compound, named TFA·FF-OBzl (Scheme 1), the C-terminus was capped with a benzyl ester $(\mathrm{OBzl})$ group and the protonated amino group was stabilized forming an ion pair with trifluoroacetate (TFA). Obviously, aromatic interactions in TFA-FF-OBzl were weaker than on Fmoc-FF and Fmoc-FF-OFm, while the dominant role played by intermolecular electrostatic interactions in the parent FF peptide decreased considerably because of the charge shielding induced by TFA. Results showed that polar aqueous environments tend to promote the growth of TFA.FF-OBzl fibers, which coexisted with branched-like microstructures when milli-Q water was replaced by diluted $\mathrm{KCl}$ aqueous solutions $(50 \mathrm{mM})$. In contrast, non-polar environments obtained by mixing organic solvent gave place to peptide assemblies organized in plates and spherulites. ${ }^{34}$<smiles>N[C@@H](Cc1ccccc1)C(=O)N[C@@H](Cc1ccccc1)C(=O)OCc1ccccc1</smiles>

Scheme 1. Chemical structure of dipeptide TFA·FF-OBzl. 
In this work we investigate the self-assembly of a new amphiphile that, apparently, can be considered as an intermediate between Fmoc-FF and TFA.FF-OBzl. More specifically, in this peptide the C-terminal OBzl group of TFA FF-OBzl has been replaced by OFm. Thus, the resulting peptide, named TFA·FF-OFm (Scheme 2), only differs from Fmoc-FF in (1) the position and size of the aromatic capping group and (2) the stabilization of the free end through the TFA anion. Self-assembly studies have been conducted considering polar environments formed by 1,1,1,3,3,3-hexafluoro-2-propanol (HFIP):water mixtures and different peptide concentrations, temperatures, ionic strengths, and incubation times for the feeding peptide solution. Results show that the TFA·FF-OFm amphiphile self-associates into amyloid-like fibrils under well-defined conditions of concentration and temperature. The formation of these twisted structures is kinetically driven while the conventional fibers typically adopted by FF-derivatives are thermodynamically favored. Besides, the elimination of the TFA stabilizing anion to produce FF-OFm (Scheme 2) results in bundles of fibers.
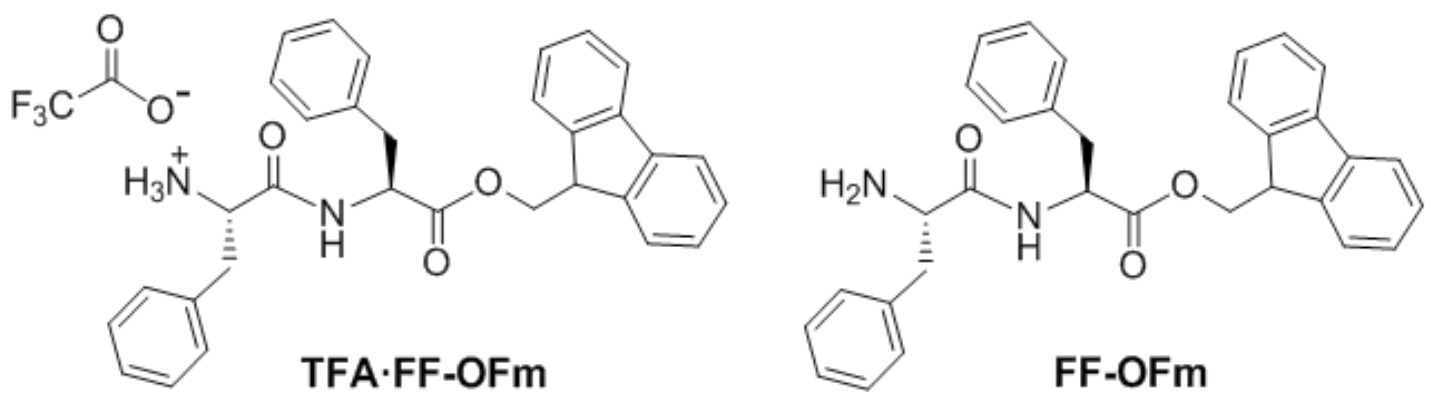

Scheme 2. Chemical structure of dipeptide FF-OFm (with either protonated or neutral amino terminus)

\section{RESULTS AND DISCUSSION}

\section{Peptide synthesis}

The compounds studied in this work, TFA·FF-OFm and FF-OFm, were synthesized according to the route shown in Figure 1. Two residues of L-Phe functionalized in the 
amino or carboxylic acid terminus as $N$-tert-butoxycarbonyl (Boc) or 9-fluorenylmethyl (Fm) ester, respectively, were coupled to give the corresponding dipeptide Boc-L-Phe-LPhe-OFm (Boc-FF-OFm). Removal of the $N$-Boc protection by treatment with trifluoroacetic acid (TFA) provided the dipeptide with a protonated amino terminus as the trifluoroacetate salt, TFA·FF-OFm. Further neutralization afforded the compound with a free neutral amino group, FF-OFm. The ${ }^{1} \mathrm{H}$ and ${ }^{13} \mathrm{C}$ NMR spectra of TFA FFOFm and FF-OFm are displayed in Figures S1-S4, the FTIR spectra in Figure S5-S6, and the high resolution mass spectrum of TFA $\cdot$ FF-OFm in Figure S7.

\section{Self-assembly of TFA·FF-OFm: from fibers to amyloid fibrils}

A stock solution $(5 \mathrm{mg} / \mathrm{mL})$ of TFA·FF-OFm in HFIP was diluted with milli-Q water, which acted as a co-solvent, to a final peptide concentration of $2 \mathrm{mg} / \mathrm{mL}(4: 6$ HFIP:water). As displayed in Figure 2, disordered fibrous peptide assemblies were obtained after slow solvent evaporation at $4{ }^{\circ} \mathrm{C}$. These consisted of fibers bundles tens to even hundreds micrometers long and variable width, which grew forming highly developed 3D entangled networks. Magnified SEM micrographs show that fibers of micrometric width were actually constituted by a dense packing of nanofibers with width of $98 \pm 17 \mathrm{~nm}$, which arranged in a braided rope-like configuration. Thus, nanofibers twisted around each other forming very homogeneous and compact braided microfibers (width: $1.3 \pm 0.4 \mu \mathrm{m}$ ) without topographic imperfections, as is evidenced in the corresponding AFM images. Importantly, high magnification SEM micrograph and AFM images clearly show that nanofibers do not fuse to form the braided microfibers but they maintain the own identity.

Reduction of the peptide concentration to $0.5 \mathrm{mg} / \mathrm{mL}$ by increasing the amount of water in the solvent:co-solvent mixture (1:9 HFIP:water) resulted in a drastic 
morphological change. Thus, TFA·FF-OFm molecules aggregate into long amyloid-like fibrils, which can be detected forming part of relatively dense bundles (Figure 3a) or as individual entitites (Figure 3b). The width of the fibril is variable, even though it typically ranges from 1.5 to $2.5 \mu \mathrm{m}$. Fibrils clearly come from the fusion of two or more thinner helical ribbons, as is clearly displayed in Figures 3c-d (red marks). More specifically, two different situations were identified in SEM micrographs: (i) two strands intertwine to form a ribbon (blue arrow in Figure 3c) that, subsequently, intertwines with another ribbon to form a fibril (red arrows in Figure 3c); or (ii) multiple strands and/or ribbons intertwine simultaneously to form the fibril (red arrows in Figures $3 c-d)$. The fusion of strands and/or helical ribbons into microfibrils is an important difference with respect to assemblies discussed above for the $2 \mathrm{mg} / \mathrm{mL}$ peptide concentrations, in which nanofibers maintained their own identity and individuality when they entangled into microfibers (Figure 2).

Amyloid-like fibrils were never detected for TFA·FF-OBzl, ${ }^{34}$ which was investigated using experimental conditions identical to those employed in the present work for TFA·FF-OFm. Thus, $2.0 \mathrm{mg} / \mathrm{mL}(4: 6 \mathrm{HFIP}$ :water) TFA·FF-OBzl solutions formed peptide nanofibers with a diameter $(\phi)$ of $\sim 250 \mathrm{~nm}$, which aligned and packed into welldefined microfibers of up to $\sim 10 \mu \mathrm{m}$. At the same time, such microfibers organized into very dense aggregates with a spike-like morphology. When the TFA·FF-OBzl concentration was reduced by increasing the polarity of the HFIP:water (i.e. adding water), the density of aggregated microfibers decreased and a very porous mesh of randomly oriented (bundled) fibers coexisted with the spike-like supramolecular structure. In any case, no amyloid-like fibril was detected, even when HFIP was replaced by other organic solvent, as for example dimethylsulfoxide and dimethylformamide. ${ }^{34}$ This observation evidences the important role played by the 
strength of $\pi-\pi$ stacking interactions in the nucleation and growing of amyloid fibrils formed by amphiphilic peptides, which have been achieved by replacing the OBzl Cterminal capping group of TFA $\cdot F F-O B z l$ by OFm. Thus, the very high hydrophobicity and aromaticity of the latter capping group with respect to the former one promote the association of the small peptide molecules into unique amyloid-like structures.

Parallel and antiparallel molecular arrangements in a $\beta$-sheet structure can be distinguished by FTIR spectroscopy. It is well known that intermolecular hydrogen bonding interactions can be established by analyzing the amide I band, which is associated to the stretching vibration of the main chain carbonyl groups. The wavenumber of this band is comprised between $1600 \mathrm{~cm}^{-1}$ and $1700 \mathrm{~cm}^{-1}$, the exact position depending on the formation of intra- or inter-molecular specific interactions, such as hydrogen bonds. ${ }^{35,36}$ The antiparallel $\beta$-sheet arrangement exhibits two Amide I bands at around $1685 \mathrm{~cm}^{-1}$ (weak) and $1632 \mathrm{~cm}^{-1}$ (strong), whereas a single band at around $1645 \mathrm{~cm}^{-1}$ is characteristic of the parallel $\beta$-sheet disposition. The random molecular conformation is distinguished by a single band around $1654 \mathrm{~cm}^{-1}$.

The FTIR spectrum, which was recorded for a powder sample recovered from a preparation of TFA·FF-OFm fibrils obtained using a peptide concentration of 0.5 $\mathrm{mg} / \mathrm{mL}$, is displayed in Figure 4a. Typical amide bands indicative of hydrogen bonding interactions (e.g. amide A, amide B, amide I and amide II bands at 3310, 3064, 1671, and $1554 \mathrm{~cm}^{-1}$, respectively) can be detected together with free carboxilate bands at $1716(\mathrm{C}=\mathrm{O}$ stretching $)$ and $1100(\mathrm{CO}-\mathrm{O}$ stretching $) \mathrm{cm}^{-1}$, respectively. Amide $\mathrm{I}$ band appears overlapped with the $\mathrm{C}=\mathrm{O}$ stretching of the carbamate unit giving rise to a strong signal at $1671 \mathrm{~cm}^{-1}$. These results suggest that TFA $\cdot F F-O F m$ adopts a $\beta$-sheet structure with an antiparallel disposition of hydrogen bonded molecules. 
Spectra of individual crystals could be acquired using polarized synchrotron radiation. Specifically, individual crystals with a specific orientation were selected to record the corresponding spectra. Figure $4 \mathrm{~b}$ shows an optical micrograph of a selected region where typical spherulitic aggregates (Figure 4c) and twisted amyloid-like fibrils (Figure 4d) can be detected. Analyses were performed with a minimum of 10 crystals, which were selected with an orientation parallel to the plane of polarization (i.e. horizontal disposition for a $0^{\circ}$ polarized spectrum). Figure $4 \mathrm{e}$ clearly shows a strong intensity for the $1674 \mathrm{~cm}^{-1}$ band, suggesting that $\mathrm{C}=\mathrm{O}$ bonds of both amide and carbamate groups are oriented parallel to the helical axis. On the contrary, the spectrum taken with a polarization of $90^{\circ}$ shows the practical disappearance of the indicated band and also a clear enhancement of a band at $1657 \mathrm{~cm}^{-1}$. The latter can be related to TFA carboxylate groups, which seems to be more randomly distributed. It is worth noting that at $90^{\circ}$ polarization the band at $1674 \mathrm{~cm}^{-1}$ splits into two bands at $1678 \mathrm{~cm}^{-1}$ (carbamate) and $1668 \mathrm{~cm}^{-1}$ (Amide I). Spectra recorded for single crystals allow demonstrating the antiparallel arrangement of molecules. To complement microscopy and microbeam synchrotron radiation infrared spectroscopy, Congo red staining was performed for $0.5 \mathrm{mg} / \mathrm{mL}$ TFA $\cdot \mathrm{FF}-\mathrm{OFm}$ structures. As observed by polarized microscopy (Figure 3e), the birefringence associated to such staining, which is a diagnosis for amyloid fibril formation, ${ }^{37}$ was interfered by the birefringence of highly oriented fibers.

In order to obtain information about the structure of the aggregates in the first stages of the assembly process, circular dichroism (CD) spectra were recorded at very diluted peptide solution $(0.05 \mathrm{mg} / \mathrm{mL})$ in 1:99 HFIP:water. Figures 5a and $5 \mathrm{~b}$ displays the $\mathrm{CD}$ spectra in a heating run from $30{ }^{\circ} \mathrm{C}$ to $90{ }^{\circ} \mathrm{C}$ and in a cooling run from $90{ }^{\circ} \mathrm{C}$ to $10{ }^{\circ} \mathrm{C}$, respectively. As it can be seen, the spectra exhibited very small variations with the 
temperature. The negative bands at 194 and $209 \mathrm{~nm}$ suggests a mixture of random and turn structures while the positive maxima at around $220 \mathrm{~nm}$ indicates the presence of $\pi$ $\pi$ stacking, which has been attributed to the OFm capping units. Regarding to the latter band, it is worth noting that it was found to be much less intense for FF nanotubes, in which $\pi-\pi$ stacking interactions only involve the phenyl side groups, and completely inexistent for non-self-assembling Ala-Ala dipeptide. ${ }^{15}$ Thus, the potential for aromatic stacking interactions introduced by the OFm is expected to play a crucial role in the peptide assembly, including the formation of amyloid-like fibrils. Moreover, at very diluted concentrations (i.e. $0.05 \mathrm{mg} / \mathrm{mL}$ in 1:99 HFIP:water), in which amyloid-like fibrils were not detected, the $\pi-\pi$ stacking could be even the driving force. This is consistent with the poorly defined fiber-like agglomerates, with a length of a few tens of micrometers long, heterogeneously distributed onto the surface observed after solvent drying (Figure S8).

\section{Kinetics versus thermodynamic stability of TFA-FF-OFm amyloid-like fibrils}

In the previous section we showed that TFA·FF-OFm molecules formed twisted amyloid-like fibrils when the peptide concentration decreased from $2.0 \mathrm{mg} / \mathrm{mL}$, which provided well-defined microfibers, to $0.5 \mathrm{mg} / \mathrm{mL}$. This feature suggests that the nucleation and growth of amyloid structures comes from the competency between different parameters that affect the kinetics and the thermodynamics of the selfassembly process. In order to provide a deeper understanding of the factors that favor the association of TFA.FF-OFm molecules into well-organized supramolecular amyloid-like fibrils, the structures formed after altering selected experimental conditions have been analyzed. 
Figures 6a-b display the supramolecular structures obtained when a $0.5 \mathrm{mg} / \mathrm{mL}$ TFA·FF-OFm solution in 1:9 HFIP:water was stored at rest for 12 days at room temperature, before placing the solution drops on microscope coverslips for drying at 4 ${ }^{\circ} \mathrm{C}$. Thus, during the first period the self-assembly of TFA.FF-OFm was thermodynamically controlled, while solvent evaporation imposes a kinetic control after deposition onto the glass substrate. As it can be seen in Figure 6a, long plates of approximately $2 \mu \mathrm{m}$ width that, apparently, come from the hierarchical assembly of nanowires were obtained. Although some of these plates resemble deformed microfibers because of their dimensions, twisted fibrils were completely absent when the peptide solution was incubated to promote the pre-assembly of thermodynamically favored structures. This feature indicates that the twisted assembly of the small amphiphile under study is kinetically driven when the medium evaporates from low concentration solutions.

On the other hand, stacked braid-like microstructures were observed at the edges of glass coverslips (Figure 6b). Although the length and width of these braids was variable, they tend to organize in very compact aggregates. The dipeptide capped with two fluorenyl functionalities, Fmoc-FF-OFm, also self-assembled into compact stacked braid-like microstructures from HFIP:water solutions with the peptide concentrations ranging from 0.5 to $2 \mathrm{mg} / \mathrm{mL}^{29}$ Moreover, highly aromatic peptides with a higher number of F-residues, as for example Fmoc-FFF-OFm, ${ }^{29}$ Fmoc-FFFF-OFm $^{29}$ and Fmoc-FFFF-OBzl, ${ }^{9}$ also exhibited very similar morphologies. These observations suggest that aromatic capping groups play a crucial role in the interfacial mechanism that systematically stabilizes such unique microstructure at the edges of the coverslip.

In order to corroborate that TFA·FF-OFm amyloid-like fibrils are not thermodynamically stable, their temporal stability was evaluated. For this purpose, 
microstructures like those displayed in Figure 3 were prepared as obtained in the previous subsection (i.e. using a $0.5 \mathrm{mg} / \mathrm{mL}$ peptide 1:9 HFIP:water solution). The samples were stored at rest during six weeks at $4{ }^{\circ} \mathrm{C}$. After this time, the twist of the fibrils decreased or even disappeared, as is reflected in the representative SEM micrographs displayed in Figure 6c. These results indicate the thermodynamic stability of TFA.FF-OFm helical ribbons and amyloid-like fibrils is lower than that of fibers, even though their formation is kinetically promoted under controlled conditions.

\section{Elimination of the stabilizing TFA anion}

Disruption of the TFA.FF-OFm ion pair was achieved by neutralizing with $5 \%$ aqueous $\mathrm{NaHCO}_{3}$, which yielded $\mathrm{FF}-\mathrm{OFm}$ (Figure 1). The $\mathrm{CD}$ spectrum at room temperature (Figure 5c) shows important differences with respect to TFA $\cdot \mathrm{FF}-\mathrm{OFm}$, suggesting changes in secondary structure due to the elimination of the stabilizing counteranions. Thus, the CD spectrum, which shows a positive maximum at $197 \mathrm{~nm}$ while a negative shoulder and peak appear at 208 and $222 \mathrm{~nm}$, respectively, indicates the complicated secondary structure of the neutralized peptide in diluted $(0.05 \mathrm{mg} / \mathrm{mL})$ 1:99 HFIP:water solution. This may be not uniform $\beta$-sheet and/or $\alpha$-helical.

The self-assembly behavior of the resulting $\mathrm{N}$-uncapped compound was examined at $4{ }^{\circ} \mathrm{C}$ considering both 4:6 and 1:9 HFIP:water solutions, which correspond to 2 and 0.5 $\mathrm{mg} / \mathrm{mL}$ peptide concentrations (Figure $7 \mathrm{a}$ and $7 \mathrm{~b}$, respectively). As it can be seen, solvent evaporation from the solution with the highest peptide concentration resulted in assemblies similar to those described for TFA·FF-OFm (Figure 2). These consist of disordered clusters of relatively long fibers and varying thicknesses. Fibers of micrometric thickness are constituted by well-defined nanofibers that assemble hierarchically forming very compact $3 \mathrm{D}$ structures (Figure $7 \mathrm{a}$ ). The similarity with 
TFA.FF-OFm structures is not maintained when the peptide concentration decreases to $0.5 \mathrm{mg} / \mathrm{mL}$. While TFA · FF-OFm forms amyloid fibrils (Figure 3), FF-OFm selfassembles into disordered groups of nanofibers of thickness ranging from $\sim 50 \mathrm{~nm}$ to a few hundred nanometers (Figure 7b). Each of these fibers is an individual entity rather than a hierarchical organization of thinner sub-entities, as occurred in assemblies derived from $2 \mathrm{mg} / \mathrm{mL}$ peptide solutions. Moreover, the characteristic regular twist of helical ribbons and amyloid fibrils is not detected in FF-OFm fibers.

Structural analyses by infrared micro-spectroscopy were easier for FF-OFm than for TFA.FF-OFm since signals corresponding to carboxylate salts are not present. The region selected for this study corresponds to a group of fibers with dimensions of several microns long and less than $50 \mathrm{~nm}$ wide, as is displayed in the SEM micrographs shown in Figure 7c. More specifically, zones bearing horizontally and vertically oriented fibers, which are marked in the optical micrograph (Figure 7d), were both examined by synchrotron microbeam polarized spectroscopy. Figure 7e indicates that the spectra of zones with horizontally- and vertically oriented fibers are clearly different. Thus, a predominant band at $1674 \mathrm{~cm}^{-1}$ and a clear shoulder at $1663 \mathrm{~cm}^{-1}$ were characteristic of fibers with a horizontal orientation when observed with $0^{\circ}$ polarized light. On the contrary, the intensity of the main band clearly diminished when observed with $90^{\circ}$ polarized light. These observations clearly indicate a parallel arrangement of carbamate $\mathrm{C}=\mathrm{O}$ groups to the crystal long axis and a sheet structure with an antiparallel disposition of molecules, as above discussed for the TFA.FF-OFm derivative (Figure 4e). Note that the carboxylate band at $1657 \mathrm{~cm}^{-1}$ logically disappeared after the basic treatment. For the sake of completeness, it is worth noting that vertically oriented fibers observed under a polarization of $0^{\circ}$ gave rise to a spectrum with again a low intense 
band at $1674 \mathrm{~cm}^{-1}$, which supported the high orientation of these groups in the formed crystals.

\section{Structural model of amyloid-like fibrils}

As was shown above, TFA·FF-OFm assembles into amyloid-like fibrils under appropriated conditions (Figure 3). Moreover, the periodicities, as estimated from SEM micrographs, are similar for one fiber that for a set of different fibers (i.e. $11.7 \pm 0.5 \mu \mathrm{m}$ and $12.2 \pm 0.7 \mu \mathrm{m})$, supporting that the assembly is the same in all cases. Considering that microbeam synchrotron radiation infrared spectra demonstrate an antiparallel $\beta$ sheet arrangement of the peptide molecules and that CD spectroscopy results prove interactions between Fmoc units (Figure 4e and Figures 5a-b respectively), a rough structural model has been proposed for such hierarchical assembly (Figure 8). For this purpose, the TFA.FF-OFm molecule has been divided in five zones, which are schematically displayed in Figure 8a. The two zones located at the TFA counterion correspond to the trifluoromethyl and the carboxylate, which should establish favorable intermolecular van der Waals and electrostatic interactions, respectively, while the three at the peptide molecule are the charged $\mathrm{NH}_{3}{ }^{+}$at the $\mathrm{N}$-terminus, the two Phe residues and the OFm capping group. Intermolecular interactions involving the $\mathrm{NH}_{3}{ }^{+}$and $\mathrm{Fmoc}$ groups should be electrostatic and $\pi-\pi$ stacking, respectively, whereas Phe residues are expected form both hydrogen bonds and $\pi-\pi$ stacking. Kinetically driven molecular association processes are expected to be guided by unspecific electrostatic interactions, which are much stronger than specific hydrogen bonding and $\pi-\pi$ stacking interactions.

In order to favor attractive $\mathrm{COO}^{-} \cdots \mathrm{NH}_{3}{ }^{+}$inter-sheet interactions avoiding strong both $\mathrm{NH}_{3}{ }^{+}{ }^{+}{ }^{+} \mathrm{H}_{3} \mathrm{~N}$ and $\mathrm{COO}^{-\cdots}{ }^{-}$OOC repulsions, successive antiparallel $\beta$-sheets are proposed to be laterally assembled with a spatial displacement along the peptide-axis 
(Figure $8 \mathrm{~b}$ ). It is worth noting that both recuperative and progressive shearing of the sheets promote favorable electrostatic interactions, discrimination between such two models being not possible with available experimental data. In both cases, the intersheet cohesive forces involve attractive electrostatic, $\pi-\pi$ stacking and van der Waals forces. On the other hand, the change along the register of each individual antiparallel sheet is responsible of the twist characteristic of the amyloid-like fibrils (Figure 8c). This shift in the register of individual sheets facilities the intertwined assembly and subsequent fusion of helical ribbon or strands to form micrometric fibrils (Figure 8d). In spite of this, it should be remarked that the effective interaction area is always higher for cylindrical fibers (Figure 8e) than for helical ribbons (Figure 8d). Therefore, the attraction between helical ribbons is weak as compared with that between cylindrical fibers. In addition, depending on the sequence and/or blocking groups, cylindrical fibers made of short peptides are compatible with different molecular packings, ${ }^{9,14,38,39}$ which may also enhance the interactions among associated structures. These observations are consistent with the experiments discussed above about the kinetics versus the thermodynamic stability of amyloid fibrils. More specifically, the stronger interactions between laterally associated cylindrical fibers agree with their tendency to aggregate and precipitate from the solution, whereas the association of helical ribbons is favored from a thermodynamic point of view and, therefore, amyloid fibrils do not correspond to the lowest free energy.

It is worth noting that helical ribbons and/or amyloid-like fibrils are not formed when the OFm capping group is replaced by OBzl. ${ }^{34}$ Therefore, $\pi-\pi$ stacking interactions between aromatic OFm groups seems to be crucial for the formation of such structures. The model proposed in Figure 8, stacked OFm ladders are formed among laterally assembled molecules in the direction perpendicular to the molecular axis and the fibril 
axis. In those ladders, the distance between stacked OFm groups is expected to be defined by the protuberating $\mathrm{Ph}$ side groups of Phe residues, which probably are also involved in intermolecular $\pi-\pi$ stacking interactions with the side groups of neighboring molecules. Obviously, for the same molecular conformation the role of such stacked ladders would be much weaker for TFA·FF-OBzl, especially considering that the distance among stacked OBzl groups should be the same that in the proposed model. Indeed, TFA FF-OBzl was found to crystallize in a folded conformation, which allowed a unique structure with a segregated distribution of hydrophilic and hydrophobic regions, rather than in a conventional $\beta$-strand conformation within a $\beta$-sheet. This conformation and supramolecular organization was incompatible with the formation of amyloid-like fibrils.

\section{CONCLUSIONS}

Herein, we show the influence that increasing aromaticity has on the self-assembly behavior of amphiphilic dipeptides of sequence TFA-FF-X. In particular, we study the dipeptide capped with $\mathrm{X}=\mathrm{OFm}$, comparing the results with those reported for $\mathrm{X}=\mathrm{OBzl}$ using identical experimental conditions. ${ }^{34}$ While TFA.FF-OBzl molecules adopted a segregated organization in which the hydrophilic core of each molecule (carboxylate from TFA, amide and ester groups) was surrounded by the hydrophobic core of neighboring molecules, which explained the observed self-assembled structures, TFA.FF-OFm adopts an antiparallel $\beta$-sheet structure that allows the formation of amyloid-like fibrils at appropriate peptide concentration $(0.5 \mathrm{mg} / \mathrm{mL})$. However, this structure, which results from a kinetically driven self-aggregation process, is thermodynamically less stable than non-twisted regular fibers. As it is usual for Phecontaining peptides, the self-assembly of TFA·FF-OFm displayed concentration- 
dependent polymorphism. This observation indicates that $\pi-\pi$ stacking interaction play a decisive role in the self-assembly process, including the amyloid fibril formation. The self-assembly of TFA FF-OFm into amyloid fibrils opens new doors for the design of FF-based materials.

\section{SUPPORTING INFORMATION}

The Supporting Information is available free of charge on the ACS Publications website.

Experimental methods, ${ }^{1} \mathrm{H}-,{ }^{13} \mathrm{C}$ - and ${ }^{19} \mathrm{~F}-\mathrm{NMR}$ spectra, FTIR spectra, high resolution mass spectra and additional SEM micrographs.

\section{ACKNOWLEDGEMENTS}

Authors acknowledge MINECO/FEDER (MAT2015-69367-R, MAT2015-69547-R and CTQ2013-40855-R), Agència de Gestió d'Ajuts Universitaris i de Recerca (2017SGR359) and Gobierno de Aragón - FEDER (research group Aminoacidos y Peptidos E19_17R) for financial support. Support for the research of C.A. was received through the prize "ICREA Academia" for excellence in research funded by the Generalitat de Catalunya.

\section{REFERENCES}

(1) Okesola, B.; Mata, A. Multicomponent Self-Assembly as a Tool to Harness New Properties from Peptides and Proteins in Material Design. Chem. Soc. Rev. 2018, 47, 3721-3736. 
(2) O’Leary, L. E. R.; Fallas, J. A.; Bakota, E. L.; Kang, M. K.; Hargenink, J. D. MultiHierarchical Self-Assembly of a Collagen Mimetic Peptide from Triple Helix to Nanofibre and Hydrogel. Nat. Chem. 2011, 3, 821-828.

(3) Burgess, N. C.; Sharp, T. H.; Thomas, F.; Wood, C. W.; Thomson, A. R.; Zaccai, N. R.; Brady, R. L.; Serpell, L. C.; Woolfson, D. N. Modular Desing of SelfAssembling Peptide-Based Nanotubes. J. Am. Chem. Soc. 2015, 137, 10554-10562.

(4) Schnaider, L.; Brahmachari, S.; Schmidt, N. W.; Mensa, B.; Shasam-Niv, S.; Bychenko, D.; Adler-Abramovich, L.; Shimon, L. J. W.; Kolusheva, S.; DeGrado, W. F.; Gazit, E. Self-Assembling Dipeptide Antibacterial Nanostructures with Membrane Disrupting Activity. Nat. Commun. 2017, 8, 1365.

(5) Dinesh, B.; Squillaci, M. A.; Ménard-Moyon, C.; Samorı, P.; Bianco, A. SelfAssembly of Diphenylalanine Backbone Homologues and Their Combination with Functionalized Carbon Nanotubes. Nanoscale 2015, 7, 15873-15879.

(6) Reches, M.; Gazit, E. Casting Metal Nanowires within Discrete Self-Assembled Peptide Nanotubes. Science 2003, 300, 625-627.

(7) Arnon, Z. A.; Vitalis, A.; Levi, A.; Michaels, T. C. T.; Caflisch, A.; Knowles, T. P. J.; Adler-Abramovich, L.; Gazit, E. Dynamic Microfluidic Control of Supramolecular Peptide Self-Assembly. Nat. Commun. 2016, 7, 13190.

(8) Mayans, E.; Casanovas, J.; Gil, A.; Jimenez, A.; Cativiela, C.; Puiggalí, J.; Alemán, C. Diversity and Hierarchy in Supramolecular Assemblies of Triphenylalanine: From Laminated Helical Ribbons to Toroids. Langmuir 2017, 33, 4036-4048.

(9) Mayans, E.; Ballano, G.; Casanovas, J.; Díaz, A.; Pérez-Madrigal, M. M.; Estrany, F.; Puiggalí, J.; Cativiela, C.; Alemán, C. Self-Assembly of Tetraphenylalanine Peptides. Chem. Eur. J. 2015, 21, 16895-16905. 
(10) Yemini, M.; Reches, M.; Rishpon, J.; Gazit, E. Novel Electrochemical Biosensing Platform Using Self-Assembled Peptide Nanotubes. Nano Lett. 2005, 5, 183-186.

(11) Fan, Z.; Sun, L.; Huang, Y.; Wang, Y.; Zhang, M. Bioinspired Fluorescent Dipeptide Nanoparticles for Targeted Cancer Cell Imaging and Real-Time Monitoring of Drug Release. Nat. Nanotechnol. 2016, 11, 388-394.

(12) Mizrahi, M.; Zakrassov, A.; Lerner-Yardeni, J.; Ashkenasy N. Charge Transport in Vertically Aligned, Self-Assembled Peptide Nanotube Junctions. Nanoscale 2012, 4, 518524.

(13) Nguyen, V.; Zhu, R.; Jenkins, K.; Yang, R. Self-Assembly of Diphenylalanine Peptide with Controlled Polarization for Power Generation. Nat Commun. 2016, 7, 13566.

(14) Görbitz, C. H. The Structure of Nanotubes Formed by Diphenylalanine, the Core Recognition Motif of Alzheimer's $\beta$-Amyloid Polypeptide. Chem. Commun. 2006, $2332-2334$.

(15) Adler-Abramovich, L.; Reches, M.; Sedman, V. L.; Allen, S.; Tendler, S. J. B.; Gazit, E. Thermal and Chemical Stability of Diphenylalanine Peptide Nanotubes: Implications for Nanotechnological Applications. Langmuir 2006, 22, 1313-1320.

(16) Reches, M.; Gazit, E. Designed Aromatic Homo-Dipeptides: Formation of Ordered Nanostructures and Potential Nanotechnological Applications. Phys. Biol. 2006, 3, S10-S19.

(17) Reches, M.; Gazit, E. Formation of Closed-Cage Nanostructures by SelfAssembly of Aromatic Dipeptides. Nano Lett. 2004, 4, 581-585.

(18) Yan, X.; Li, J.; Möhwald, H. Self-Assembly of Hexagonal Peptide Microtubes and Their Optical Waveguiding. Adv. Mater. 2011, 23, 2796-2801.

(19) Raeburn, J.; Zamith-Cardoso, A.; Adams, D. J. The Importance of the SelfAssembly Process to Control Mechanical Properties of Low Molecular Weight Hydrogels. Chem. Soc. Rev. 2013, 42, 5143-5156. 
(20) Mahler, A.; Reches, M.; Rechter, M.; Cohen, S.; Gazit, E. Rigid, SelfAssembled Hydrogel Composed of a Modified Aromatic Dipeptide. Adv. Mater. 2006, $18,1365-1370$.

(21) Amdursky, N.; Orbach, R.; Gazit, E.; Huppert, D. Probing the Inner Cavities of Hydrogels by Proton Diffusion. J. Phys. Chem. C 2009, 113, 19500-19505.

(22) Smith, A. M.; Williams, R. J.; Tang, C.; Coppo, P.; Collins, R. F.; Turner, M. L.; Saiani, A.; Ulijn, R. V. Fmoc-Diphenylalanine Self Assembles to a Hydrogel via a Novel Architecture Based on $\pi-\pi$ Interlocked $\beta$-Sheets. Adv. Mater. 2008, 20, 3741.

(23) Tang, C.; Smith, A. M.; Collins, R. F.; Ulijn, R. V.; Saiani, A. FmocDiphenylalanine Self-Assembly Mechanism Induces Apparent $\mathrm{p} K_{\mathrm{a}}$ Shifts. Langmuir 2009, 25, 9447-9453.

(24) Zhou, M.; Smith, A. M.; Das, A. K.; Hodson, N. W.; Collins, R. F.; Ulijn, R. V.; Gough, J. E. Self-Assembled Peptide-Based Hydrogels as Scaffolds for AnchorageDependent Cells. Biomaterials 2009, 30, 2523-2530.

(25) Raeburn, J.; Pont, G.; Chen, L.; Cesbron, Y.; Levy, R.; Adams, D. J. FmocDiphenylalanine Hydrogels: Understanding the Variability in Reported Mechanical Properties. Soft Matter 2012, 8, 1168-1174.

(26) Dudukovic, N. A.; Zukoski, C. F. Mechanical Properties of Self-Assembled Fmoc-Diphenylalanine Molecular Gels. Langmuir 2014, 30, 4493-4500.

(27) Raeburn, J.; Mendoza-Cuenca, C.; Cattoz, B. N.; Little, M. A.; Terry, A. E.; Cardoso, A. Z.; Griffiths, P. C.; Adams, D. J. The Effect of Solvent Choice on the Gelation and Final Hydrogel Properties of Fmoc-Diphenylalanine. Soft Matter 2015, 11, 927-935. 
(28) Jayawarna, V.; Smith, A.; Gough, J. E.; Ulijn, R. V. Three-Dimensional Cell Culture of Chondrocytes on Modified Di-Phenylalanine Scaffolds. Biochem. Soc. Trans. 2007, 35, 535-537.

(29) Mayans, E.; Ballano, G.; Casanovas, J.; del Valle, L. J.; Pérez-Madrigal, M. M.; Estrany, F.; Jiménez, A. I.; Puiggalí, J.; Cativiela, C.; Alemán, C. Hierarchical SelfAssembly of Di-, Tri- and Tetraphenylalanine Peptides Capped with Two Fluorenyl Functionalities: from Polymorphs to Dendrites. Soft Matter 2016, 12, 5475-5488.

(30) Yan, X.; Zhu, P.; Li, J. Self-Assembly and Application of DiphenylalanineBased Nanostructures. Chem. Soc. Rev. 2010, 39, 1877-1890.

(31) Lakshmanan, A.; Zhang, S.; Hauser, C. A. E. Short Self-Assembling Peptides as Building Blocks for Modern Nanodevices. Trends Biotechnol. 2012, 30, 155-165.

(32) Fleming, S.; Uljin, R. V. Design of Nanostructures Based on Aromatic Peptide Amphiphiles. Chem. Soc. Rev. 2014, 43, 8150-8177.

(33) Makam, P.; Gazit, E. Minimalistic Peptide Supramolecular Co-Assembly: Expanding the Conformational Space for Nanotechnology. Chem. Soc. Rev. 2018, $47,3406-3420$.

(34) Mayans, E.; Ballano, G.; Sendros, J.; Font-Bardia, M.; Campos, L. J.; Puiggalí, J.; Cativiela, C.; Alemán, C. Effect of Solvent Choice on the Self-Assembly Properties of a Diphenylalanine Amphiphile Stabilized by an Ion Pair. Chem.Phys.Chem. 2018, 18, 1888-1896

(35) Toniolo, C.; Palumbo, M. Solid-State Infrared Absorption Spectra and Chain Arrangement in Some Synthetic Homooligopeptides in the Intermolecularly Hydrogen-Bonded Pleated-Sheet $\beta$-Conformation. Biopolymers 1977, 16, 219-224.

(36) Krimm, S.; Bandekar, J. Vibrational Spectroscopy and Conformation of Peptides, Polypeptides, and Proteins. Adv. Protein Chem. 1986, 38, 181-364. 
(37) Hamley, I. W. Peptide Fibrillization. Angew. Chem., Int. Ed. 2007, 46, 81288147.

(38) Zanuy, D.; Poater, J.; Solà, M.; Hamley, I. W.; Alemán, C. Fmoc-RGDS based fibrils: atomistic details of their hierarchical assembly. Phys. Chem. Chem. Phys. 2016, $18,1265-1278$.

(39) López-Pérez, D. E.; Revilla, G.; Hamley, I. W.; Alemán, C. Molecular insights into aggregates made of amphiphilic Fmoc-tetrapeptides. Soft Matter 2013, 9, 11021-11032. 


\section{CAPTIONS TO FIGURES}

Figure 1. Synthesis of TFA·FF-OFm and FF-OFm (F, L-phenylalanine; Fm, 9fluorenylmethyl; TFA, trifluoroacetate). Reagents and conditions: (a) EDC, HOBt, DIPEA, $\mathrm{CH}_{2} \mathrm{Cl}_{2}, 0{ }^{\circ} \mathrm{C} 30 \mathrm{~min}, \mathrm{rt}, 24 \mathrm{~h}$; (b) TFA, $\mathrm{CH}_{2} \mathrm{Cl}_{2}, \mathrm{rt}, 1 \mathrm{~h}$; (c) $5 \%$ aqueous $\mathrm{NaHCO}_{3}$.

Figure 2. Representative SEM micrographs with (a) low and (b) high magnifications and AFM (c) height and (d) 3D topographic images $\left(40 \times 40 \mu \mathrm{m}^{2}, 20 \times 20 \mu \mathrm{m}^{2}\right.$ and $5 \times 5$ $\mu^{2}$ in left, center and right, respectively) of assemblies obtained from $2 \mathrm{mg} / \mathrm{mL}$ TFA.FF-OFm solutions in 4:6 HFIP:water at $4{ }^{\circ} \mathrm{C}$.

Figure 3. Representative SEM micrographs of helical ribbons and amyloid fibrils obtained from $0.5 \mathrm{mg} / \mathrm{mL}$ TFA.FF-OFm solutions in 1:9 HFIP:water at $4{ }^{\circ} \mathrm{C}$ : (a) dense bundle of amyloid fibrils; (b) individual amyloid fibril; (c) transition from two strands to an intertwined helical ribbon (blue arrow) and from two helical ribbons to a fused fibril (red arrows); and (d) transition from multiple strands and/or helical ribbons to a fused fibril (red arrows). (e) Polarized optical microscope images of Congo red stained structure.

Figure 4. (a) FTIR spectrum of TFA.FF-OFm with labeling of main signals. (b) Micrograph showing selected crystals obtained from $0.5 \mathrm{mg} / \mathrm{mL}$ TFA $\cdot F F-O F m$ solutions in 1:9 HFIP:water at $4{ }^{\circ} \mathrm{C}$ with a horizontal orientation. (c, d) SEM micrographs showing (c) spherulitic aggregates and (d) twisted amyloid-like fibrils. (e) Microbeam synchrotron radiation infrared (SRIR) spectrum taken with polarization at $0^{\circ}$ and $90^{\circ}$.

Figure 5. CD spectra of TFA $\mathrm{FF}-\mathrm{OFm}$ at temperatures ranging (a) from $30^{\circ} \mathrm{C}$ to 90 ${ }^{\circ} \mathrm{C}$ (heating run) and (b) from $90{ }^{\circ} \mathrm{C}$ to $10^{\circ} \mathrm{C}$ (cooling run). (c) $\mathrm{CD}$ spectra of FF-OFm at $30{ }^{\circ} \mathrm{C}$. In all cases a $0.05 \mathrm{mg} / \mathrm{mL}$ peptide solution in 1:99 HFIP:water was considered. 
Figure 6. Representative (a,d) SEM micrographs and both (b) height and (c) 3D topographic AFM images $\left(50 \times 50 \mu \mathrm{m}^{2}\right)$ of the structures obtained when a $0.5 \mathrm{mg} / \mathrm{mL}$ TFA.FF-OFm solution in 1:9 HFIP:water was stored at rest for 12 days at room temperature, before placing on microscope coverslips until dryness at $4{ }^{\circ} \mathrm{C}$ : (a-c) nanowires of micrometric length and plates; and (d) stacked braid-like microstructures located at the coverslips edges. (e) SEM of the structures obtained after store at rest for 6 weeks the amyloid-like fibrils formed from $0.5 \mathrm{mg} / \mathrm{mL}$ TFA·FF-OFm solutions in 1:9 HFIP:water at $4^{\circ} \mathrm{C}$ (Figure 3).

Figure 7. Representative SEM micrographs of structures obtained from: (a) 2 $\mathrm{mg} / \mathrm{mL}$ and (b) $0.5 \mathrm{mg} / \mathrm{mL}$ FF-OFm solutions (4:6 and 1:9 HFIP:water, respectively) at $4{ }^{\circ} \mathrm{C}$. (c) SEM micrographs showing the region used for synchrotron-based infrared micro-spectroscopy measurements. (d) Optical micrograph displaying horizontally and vertically oriented FF-OFm fibers (blue and red, respectively) selected for measurements. (e) Microbeam synchrotron radiation infrared (SRIR) spectra of FFOFm fibers with horizontal and vertical orientations, which were taken with polarizations of $0^{\circ}$ and $90^{\circ}$ (only for the horizontal orientation).

Figure 8. Structural model of TFA.FF-OFm amyloid-like fibrils: (a) Scheme displaying the five fragments used to represent TFA·FF-OFm molecules, which have been selected as a function of the chemical identity and capacity to form intermolecular interactions; (b) Recuperative (left) and progressive (right) models for the lateral assembly of antiparallel $\beta$-sheets; (c) Model for the shearing along each antiparallel $\beta$ sheet, which explains the twisting in the resulting structure; (d) Model for the fibril explaining the fusion of twisted strands or helical ribbons. (e) Lateral assembly between cylindrical fibers. 


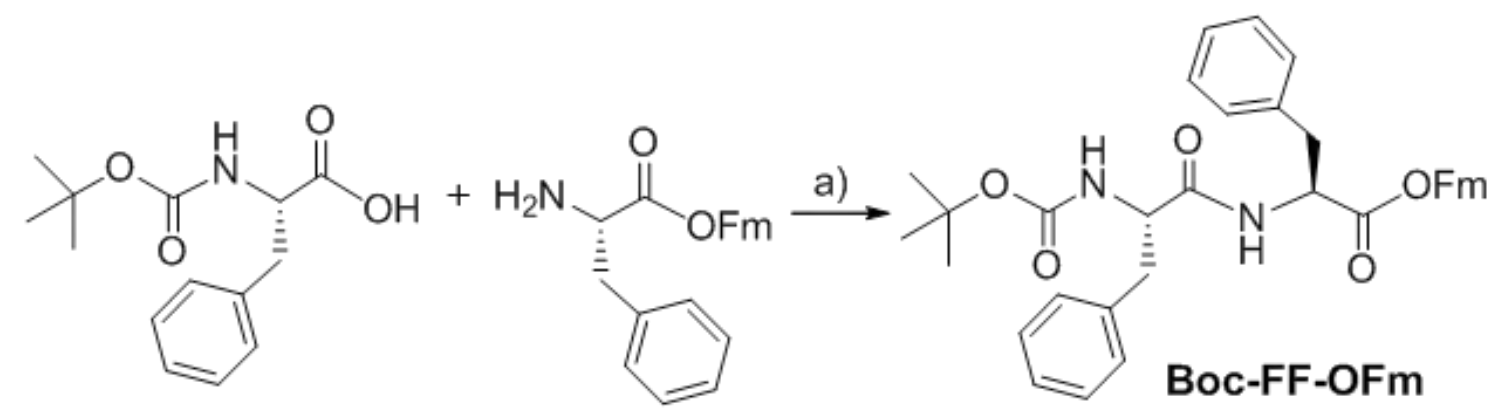

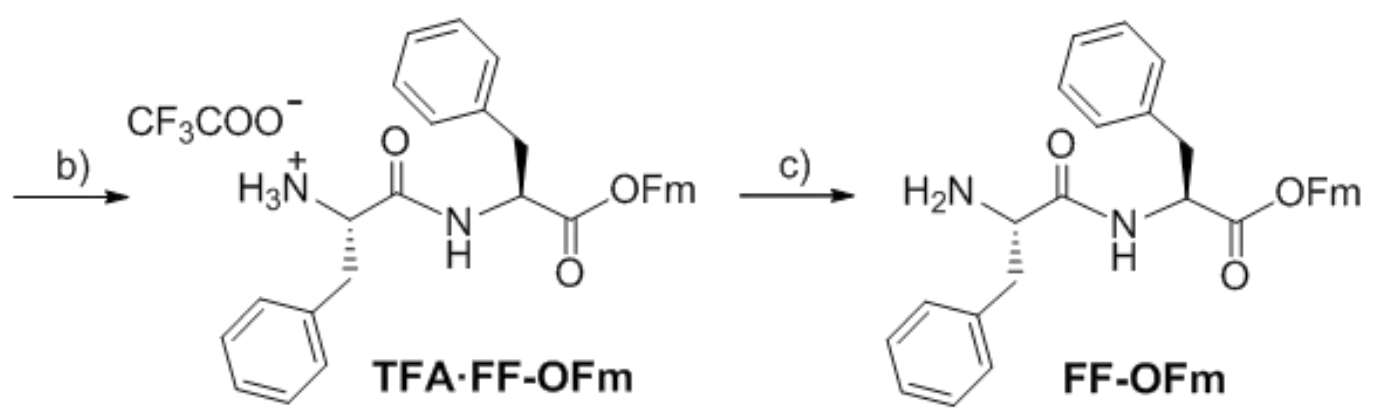

Figure 1 

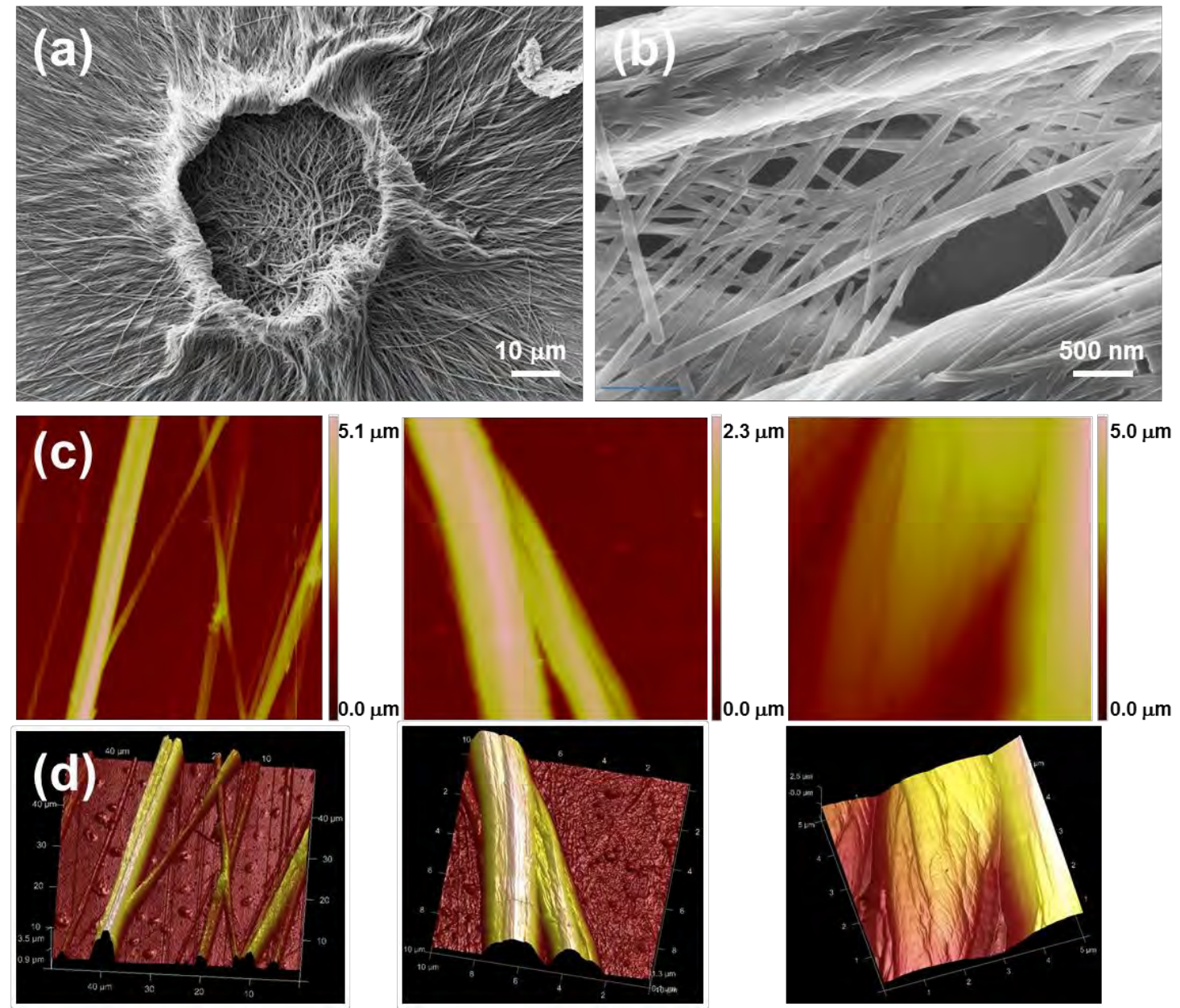

Figure 2 

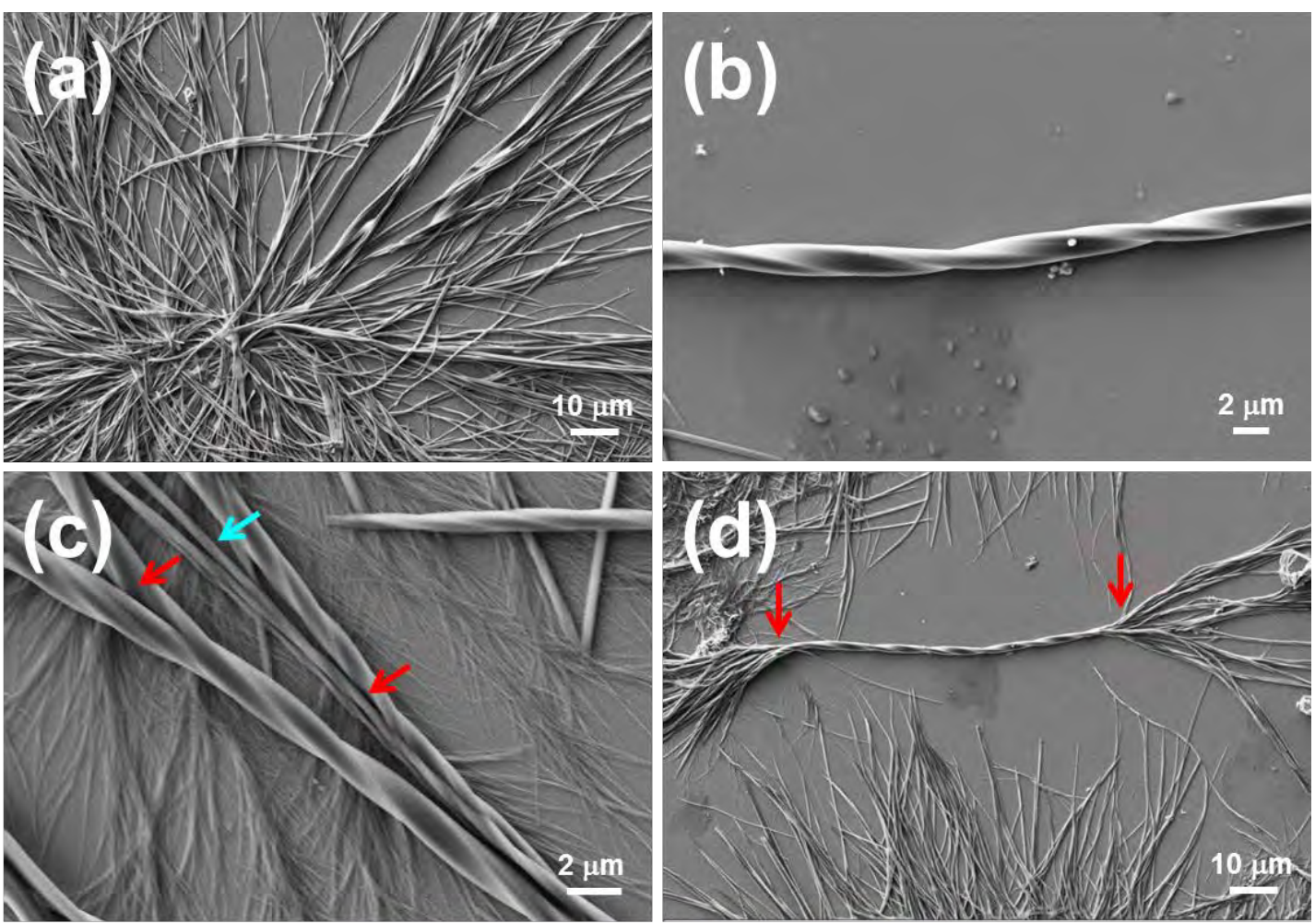

(e)

Figure 3 

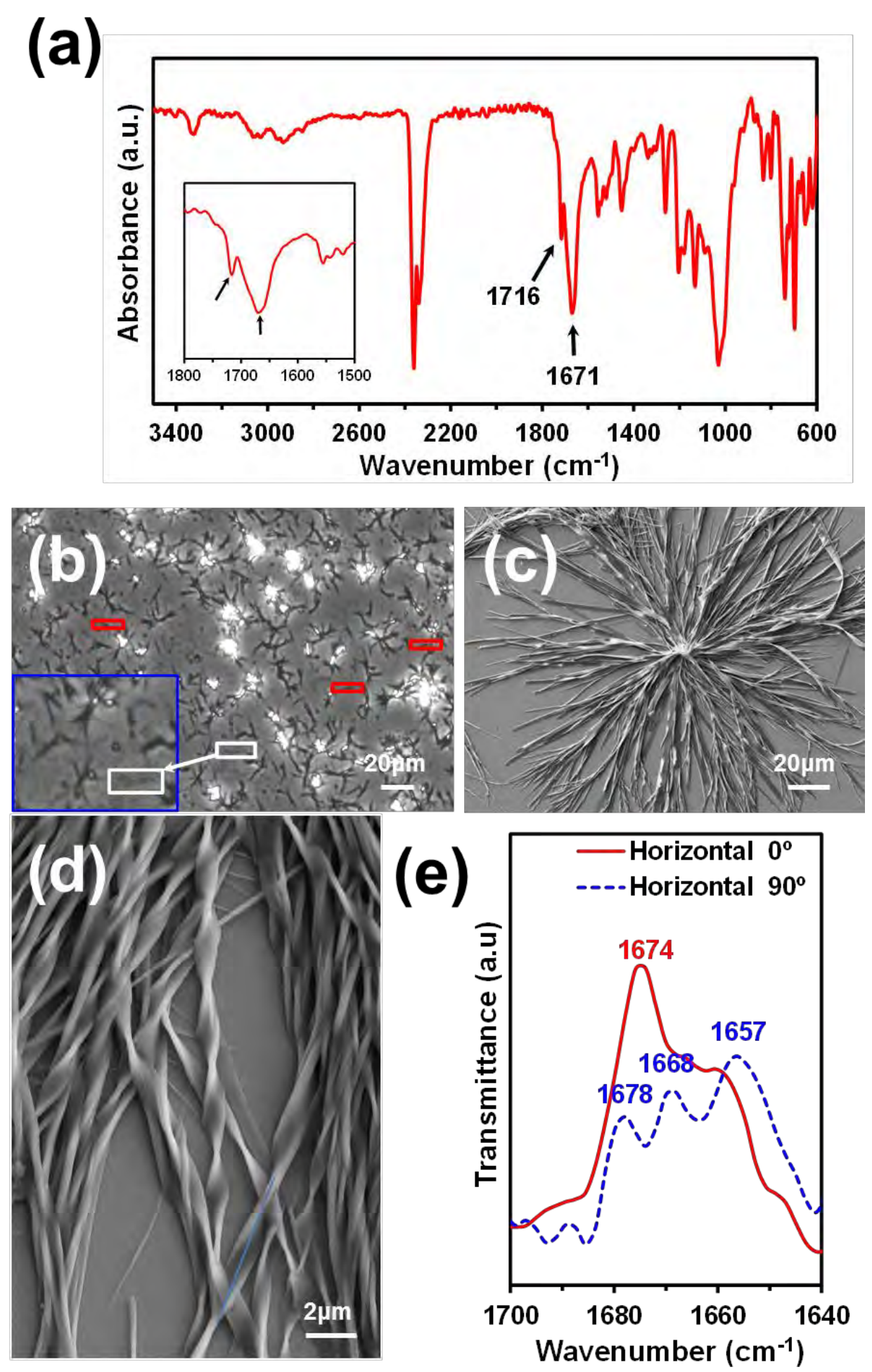

Figure 4 
(a)

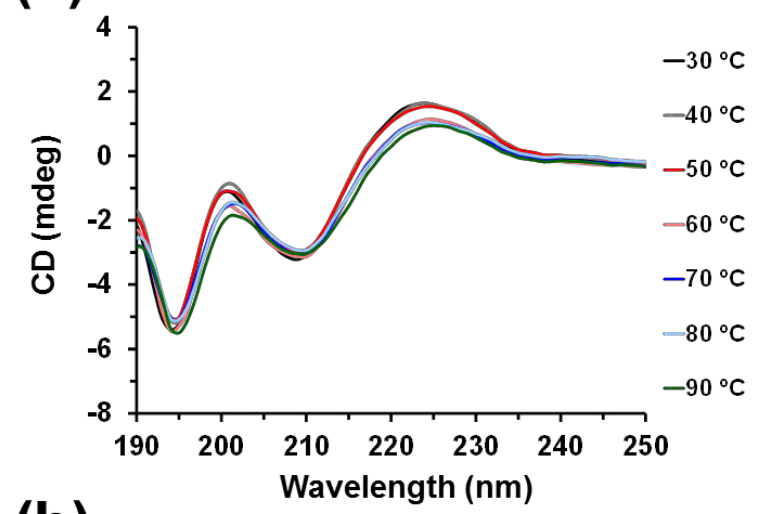

(b)

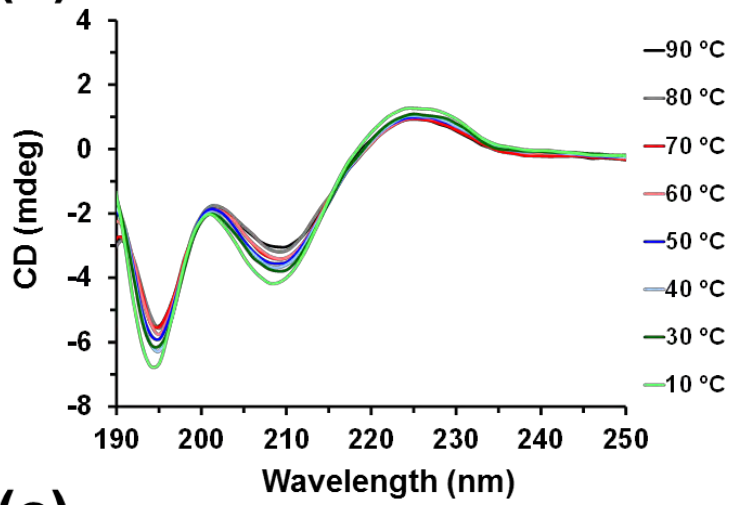

(c)

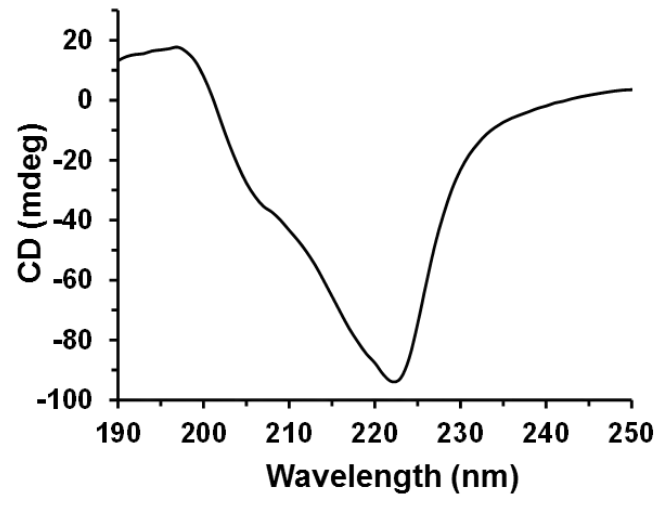

Figure 5 

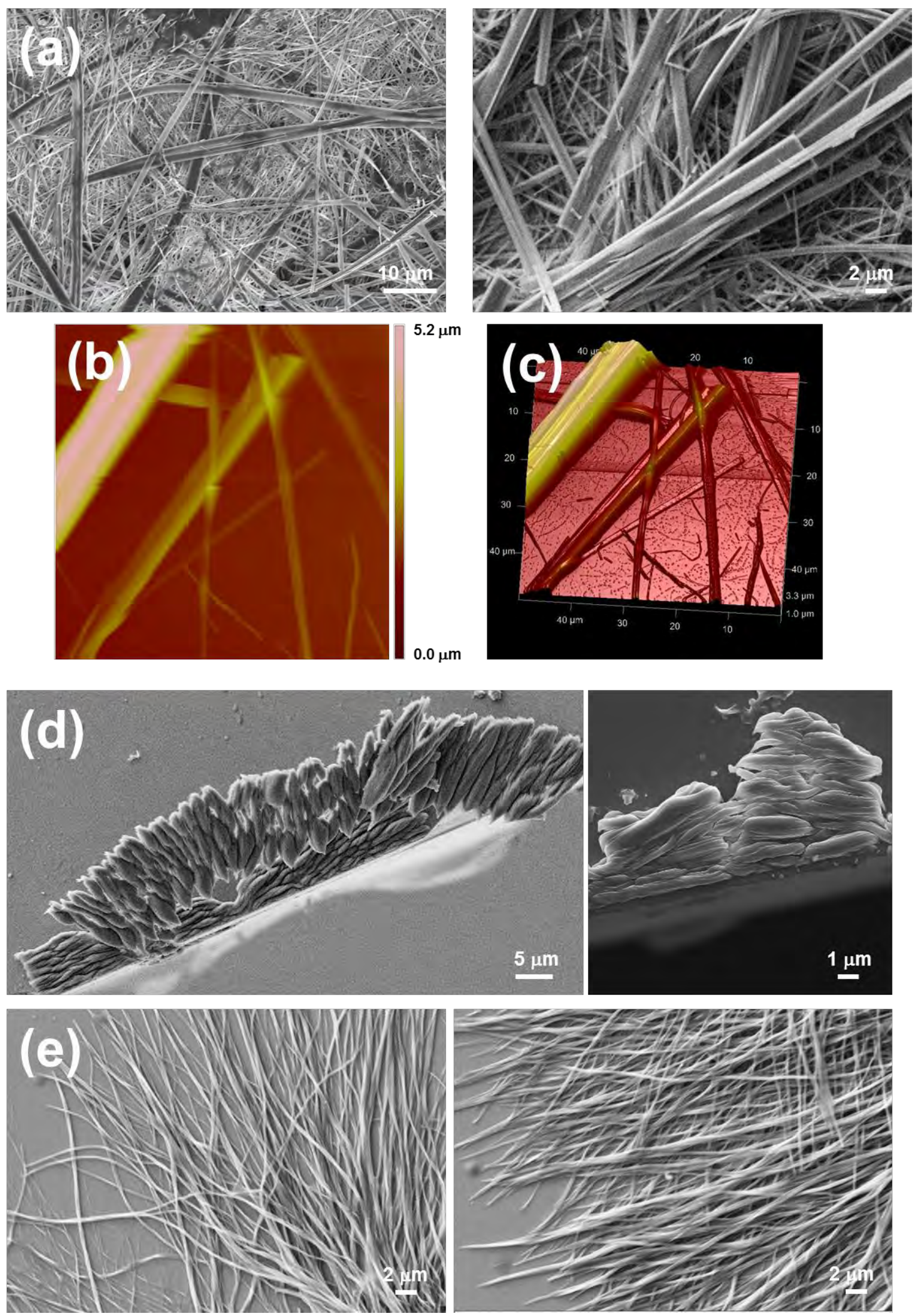

Figure 6 

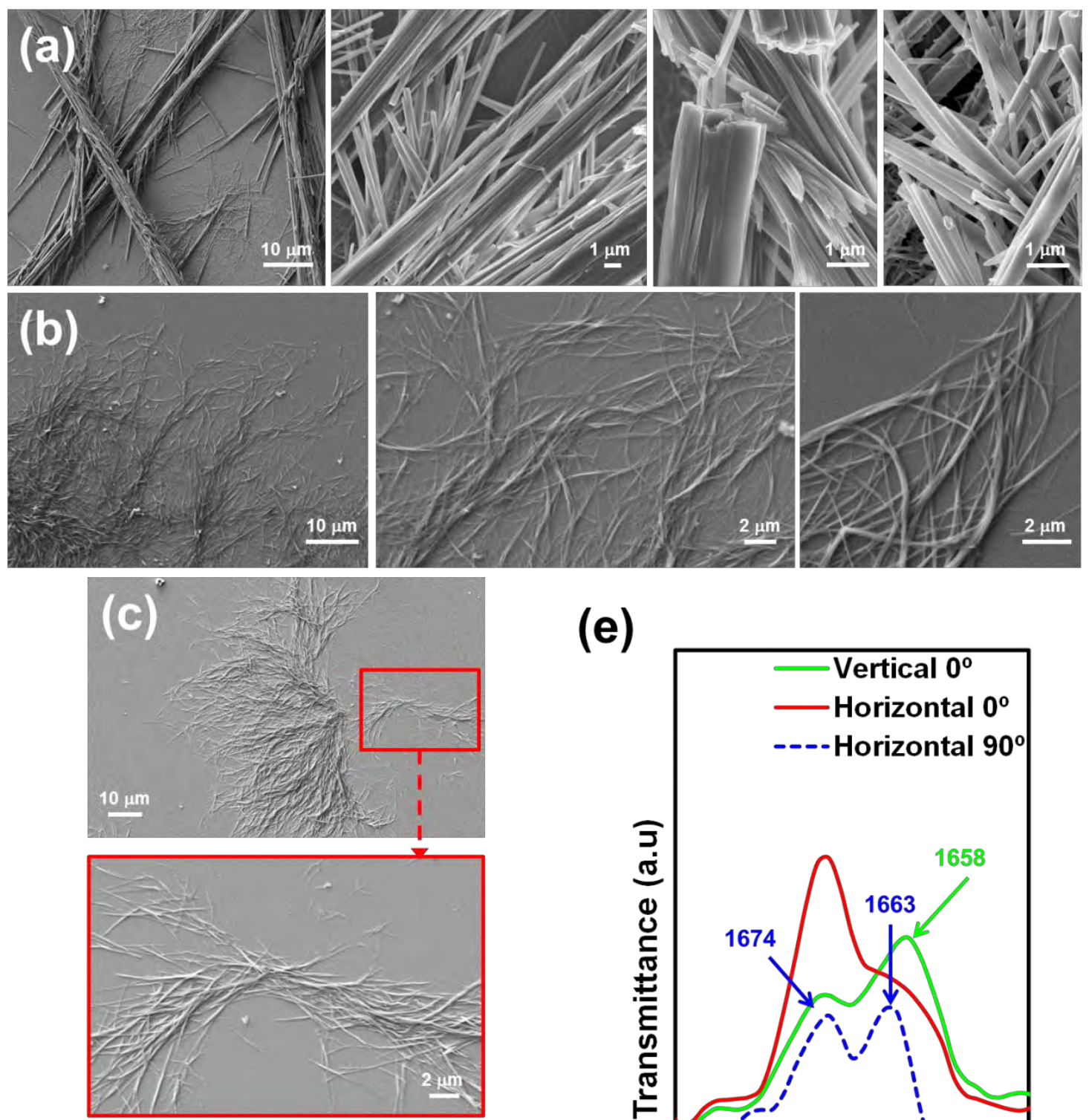

(e)
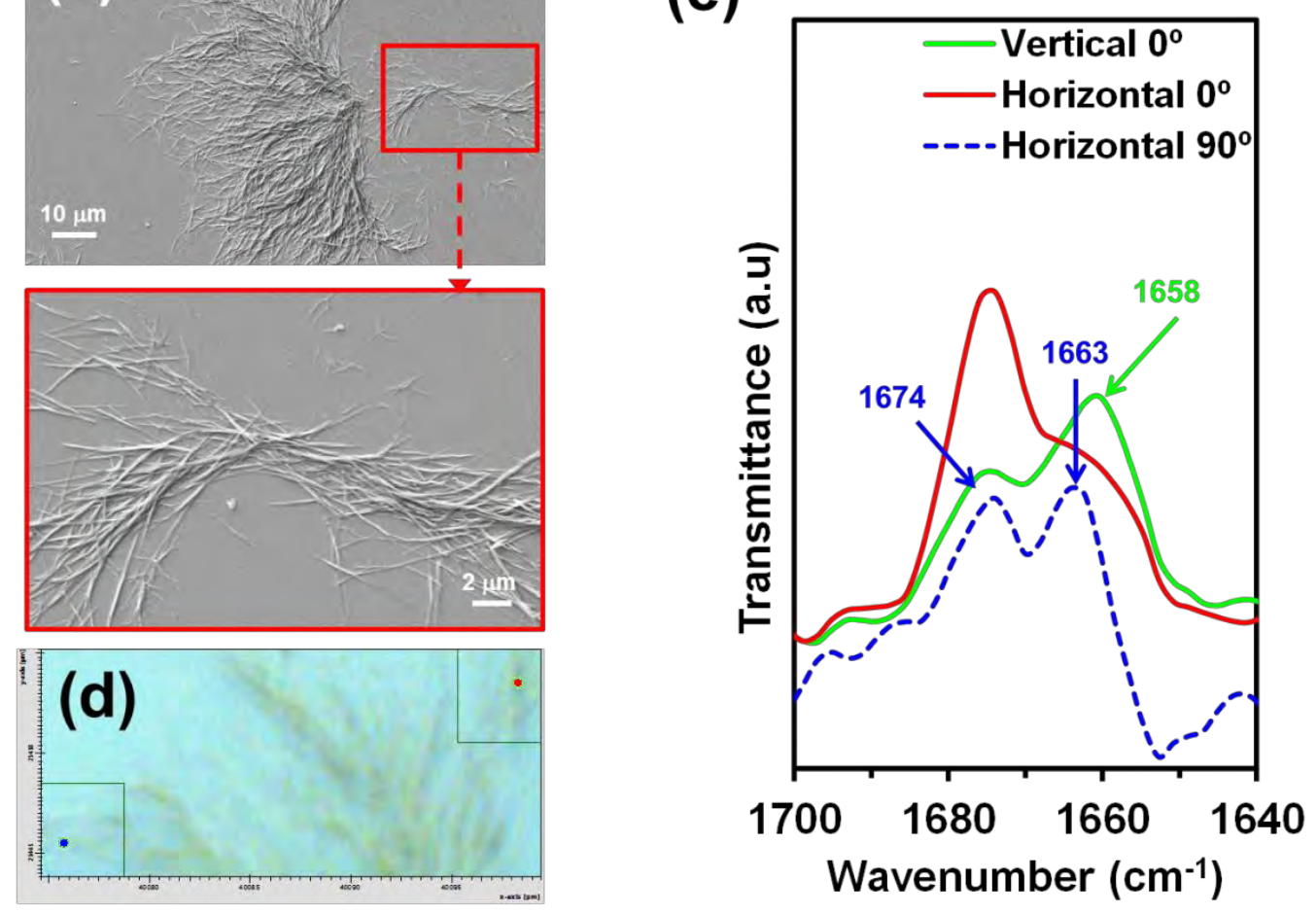

Figure 7 
(a)

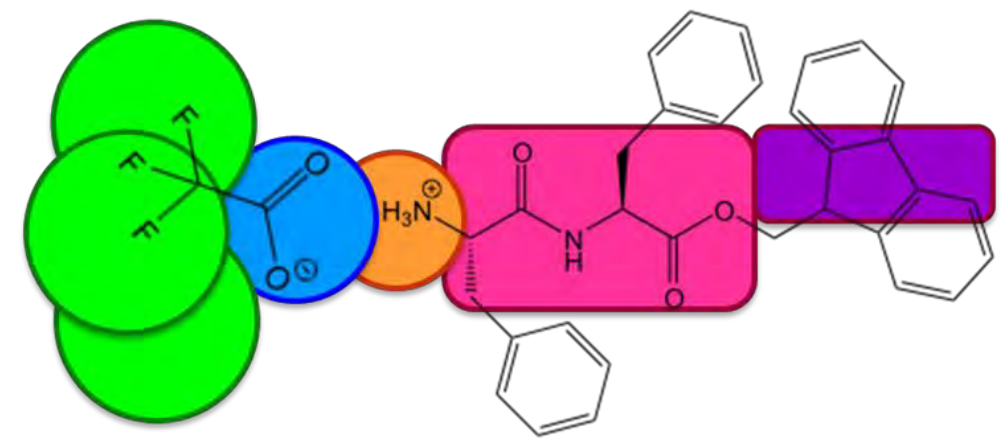

(b)

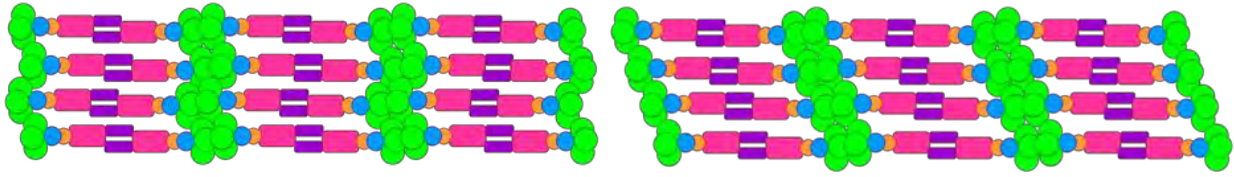

(c)

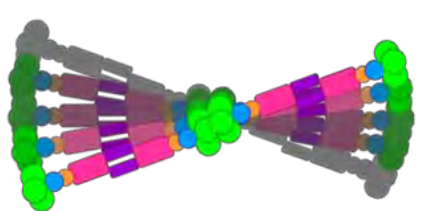

(d)

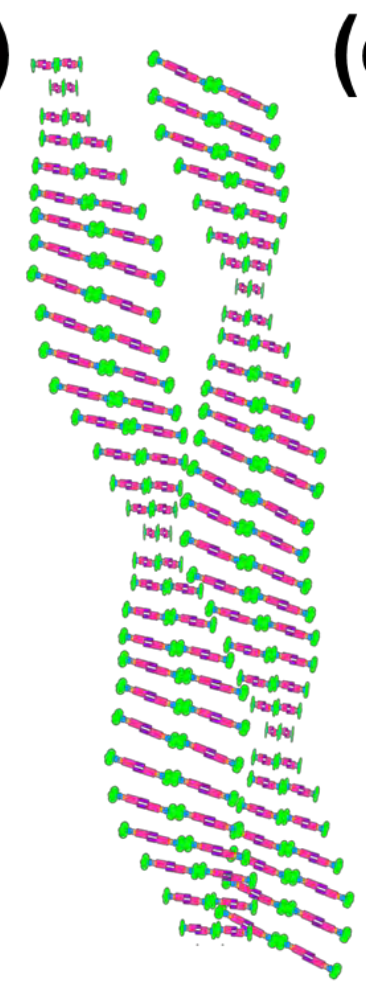

(e)
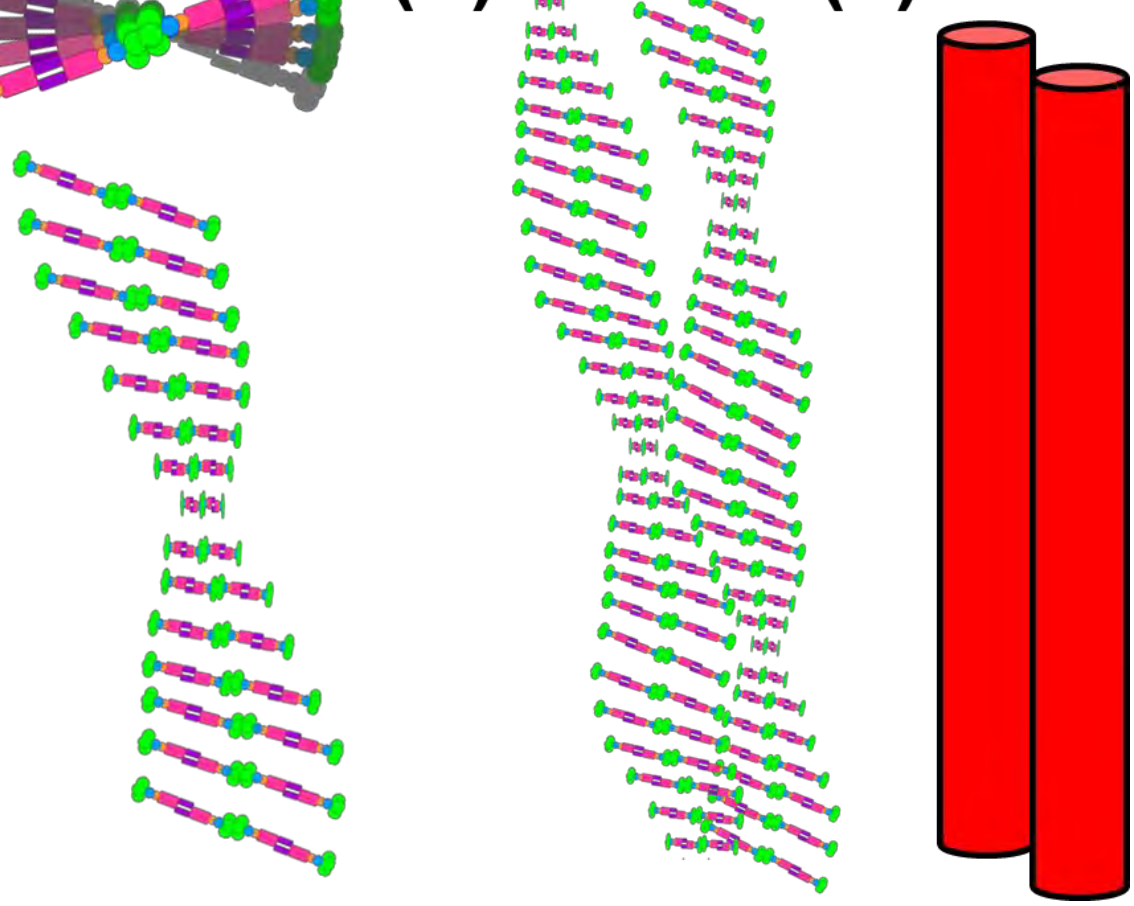

Figure 8 


\section{TOC}

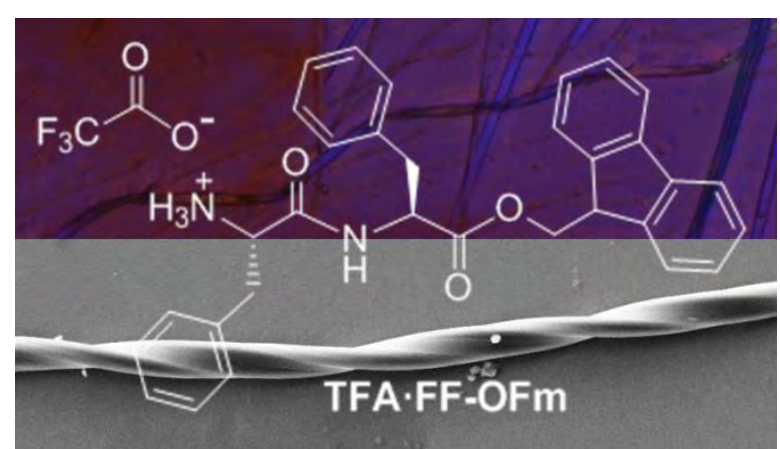

